\title{
Analysis of the Status Quo of the Demand of Service for the Aged in Hebei
}

\author{
Yahui Wü, a , Qian Zhang ${ }^{1, b}$, Haihong Xin ${ }^{1, c^{*}}$, Hongling $\mathrm{Li}^{1, \mathrm{~d}}$ \\ Yuanyuan Zuo ${ }^{1, e}$ and Nan Zang ${ }^{1, f}$ \\ ${ }^{1}$ College of Quality and Technical SupervisionHebei UniversityBaoding071000,China \\ a45695796@qq.com , b 1047680753@qq.com, ${ }^{c^{*}}$ xinhaihong498@163.com, ${ }^{d}$ sybslhl@163.com \\ e328131492@qq.com, ${ }^{\dagger} 584990331 @ q q . c o m$ \\ The corresponding author
}

Keywords: Quality of pension service; Pension model; Provision of pension service; Pension needs

\begin{abstract}
In order to improve the quality of pension service and strengthen the pertinence of the construction of the service system for the aged, this paper investigated the elderly people in Shijiazhuang and Baoding of Hebei province and then made data analysis according to the results of the survey. This article designed the questionnaire from pension model and the connotation of pension service demand two aspects. From the analysis, it's clearly to see that income level, education level, living condition and family structure will affect the elderly's willingness to choose the way of providing for the aged. What caused the elderly to pay different attention to the content of the service is different age and different income of the elderly. These trends can provide reference for the provision of pension services and the connotation construction of pension services.
\end{abstract}

\section{Introduction}

Since 2000, China has begun to enter an aging society. According to the United Nations Population Aging standard, when the population above 60 years old accounted for $10 \%$ of the total population, or 65 years old or above accounted for $7 \%$ of the total population, which means that the country entered the aging society. By 2020, the population over the age of 60 will increase to about 255 million, accounting for about $17.8 \%$ of the total population; the elderly will increase to about 29 million people; the elderly living alone and empty nest will increase to about 118 million people; the actual population living in rural areas may further deepen the degree of aging. ${ }^{[1]}$ China is the only country with an aging population of more than 100 million in the world, and the proportion of the elderly population is much shorter than that of the western developed countries. According to the " Report on the development of livable environment for the elderly in China " issued by the China Center for aging research in 2015, disability and semi disability increased rapidly in the elderly; the size of the disabled and semi disabled elderly population has exceeded 40 million people, the estimated disability population will increase to 45 million by 2020;reach 97 million 500 thousand people in 2050.Thus the increasingly severe aging situation has brought great challenges to the provision of pension services in China. This paper takes Hebei Province as an example, oriented by the needs of the elderly, providing reference for the construction of the quality system of pension service and the improvement of the supply level of pension service by investigating and analyzing the needs of the elderly.

\section{Status of China's pension service}

There are various pension models both here and abroad, such as institutional endowment, community retirement, home care, migratory bird care, old age pension and housing endowment. China's current pension service supply is lacking, mainly focused on the institutional pension, community pension and home care. The pension service system, which is based on the home, the 
community as the basis, the institution as the supplement in the construction of the old age care system was put forward during the period of 12th Five-Year. This system points out the development direction of China's pension service. Shanghai government has taken the lead in proposing the "9073" plan, that is, $90 \%$ of the elderly rely on community home care, $7 \%$ community pension, 3\% institutions pension. Then, Beijing proposed the goal of "9064" pension service development by 2020. But after several years of practice, many scholars have put forward, whether"9073" or "9064",the proportion is not consistent with the status quo of aging in China.

Li Wei believes that China has exaggerated the support status of institutional pension at the moment. According to statistics, the proportion of elderly people who choose home care for the elderly in the United States is $96.3 \%$;Sweden is $95.2 \%$;Britain is $95.5 \%$ and Japan, the most serious aging population in the world, is $98.6 \% .{ }^{[2]}$ Obviously, The cooling of institutional endowment and the return to the co

\section{The basis of questionnaire design and the selection of demand survey samples}

According to the analysis of the status quo of the pension service, the elderly's needs are affected by many factors. The demand for the elderly in different aged groups is showing a trend of diversification. In order to reflect the needs of the elderly objectively and comprehensively, the questionnaire content was divided into two parts. One is basic information, the factors such as gender, age, education level, immunity and family pension has become the development trend from the development of Japan, Europe and other countries over the years. Moreover, our country has been influenced by the traditional concept for a long time, the cognitive level of the elderly is still relatively low, especially in some rural areas. The elderly and children always think that only children filial or helpless old people choose to live in a nursing home.

In addition, the definition and explanation of home care and community pension are not very clear, which leads to the "90" model of "9073" is not clear either. In" The planning and construction of social old-age service system (2011-2015)", "home-based care services" covers life care, rehabilitation care, medical care and spiritual consolation."Community care service" is mainly for the elderly in the family, temporary or no care for the elderly community services. It is an important support for home care services, and has two functions: community day care and home care support. ${ }^{[3]}$ Those two service models overlap, responsibility can not be implemented, and form a separation and opposition relation between "home" and "community".

ome level, insurance status, physical condition, marital status and number of children are considered. The other is the investigation content, which included the choice of pension model and the pension needs of the elderly from different pension models.

At first, this paper selected the representative provinces of Shijiazhuang and Baoding in Hebei Province which are densely populated as survey sample. In order to cover different income levels, different lifestyles and achieve data balance and in line with China's national conditions, the respondents were not only from urban areas, but also from the surrounding rural areas. Then, we selected 2 communities with a lot of old people, 2 rural areas with different development status and 2 nursing homes. Then adopted the method of household survey and admission (nursing home) investigation, randomly selected 300 elderly people to conduct the questionnaire. In order to ensure the authenticity of the survey data, the old people with difficulty in filling out questionnaires were interviewed and investigated to help the elderly fill in the questionnaires. Through this survey, we collected 255 valid questionnaires.

\section{Survey results and analysis}

Basic data analysis. According to the results of the survey statistics, the survey of urban population of 179 people, rural population of 76 people. Among them, the age of 50-55 years old is 70, accounting for 28\%; 55-60 years old is 40 people, accounting for 16\%; 60-70 years old is 65 people, accounting for $25 \%$; 70 years old or above is 80 people, accounting for $31 \%$, the statistical results are shown in table 1. 
Table 1 Descriptive Statistics Table of Population according to Age to Urban and Rural Population

\begin{tabular}{|l|l|l|l|l|l|}
\hline \multirow{2}{*}{ Region } & \multicolumn{5}{|c|}{ Age } \\
\cline { 2 - 6 } & $50-55$ & $55-60$ & $60-70$ & $>70$ & Total \\
\hline Urban & 66 & 30 & 41 & 42 & 179 \\
\hline Rural & 4 & 10 & 24 & 38 & 76 \\
\hline Total & 70 & 40 & 65 & 80 & 255 \\
\hline Proportion & $28 \%$ & $16 \%$ & $25 \%$ & $25 \%$ & $100 \%$ \\
\hline
\end{tabular}

In addition, according to the income level, the number of people in towns and villages is also counted, and the statistical results are shown in table 2.

Table 2 DescriptiveStatistics of Population to Urban and Rural Population by Income Levels

\begin{tabular}{|l|l|l|l|l|l|}
\hline \multirow{2}{*}{ Region } & \multicolumn{5}{|c|}{ Income level } \\
\cline { 2 - 6 } & $<2000$ & $2000-3000$ & $3000-5000$ & $>5000$ & total \\
\hline Urban & $103(58 \%)$ & $25(14 \%)$ & $33(18 \%)$ & $18(10 \%)$ & 179 \\
\hline Rural & $47(62 \%)$ & $18(24 \%)$ & $11(14 \%)$ & 0 & 76 \\
\hline Total & $150(59 \%)$ & $43(17 \%)$ & $44(17 \%)$ & $18(7 \%)$ & 255 \\
\hline
\end{tabular}

In addition, the basic information statistics show: 150 men, accounting for 59\%;105 women, accounting for $41 \%$. From the marital status, the partner still accounts for $79 \%$; the widowed spouse accounts for $19 \%$; the single person occupies $2 \%$.From the living conditions, $14 \%$ of the elderly people who needed dressing help accounted for $21 \%$ of the total, $5 \%$ of them needed washing help, $10 \%$ of them were wheelchair dependent, and $5 \%$ of them were incontinent.

Data analysis of survey results of pension mode selection. Through the questionnaire statistics, the income level on the choice of pension mode, as shown in Table 3, income below 2000 yuan of the elderly, $85 \%$ choose family pension, $15 \%$ choose institutional pension, no one choose community pension.In the interview also showed that the cost of nursing home is generally higher, the family income restrictions make people have to choose to accept the pension at home. With the increase of income level, the elderly's choice of family pension first decreased and then increased, and the proportion of the choice of institutional pension is on the rise, as shown in figure 1.The majority of people do not understand the community pension, community pension in everyone's mind is low recognition.

Table 3 The Choice of PensionMode under Different Income Levels

\begin{tabular}{|l|l|l|l|l|}
\hline \multirow{2}{*}{ Income level } & \multicolumn{4}{|c|}{ Pension mode } \\
\cline { 2 - 5 } & Home care & Community care & Institutional & Total \\
\hline$<2000$ & 128 & 0 & 22 & 150 \\
\hline $2000-3000$ & 25 & 9 & 9 & 43 \\
\hline $3000-5000$ & 19 & 13 & 12 & 44 \\
\hline$>5000$ & 13 & 0 & 5 & 18 \\
\hline Total & 185 & 22 & 48 & 255 \\
\hline
\end{tabular}

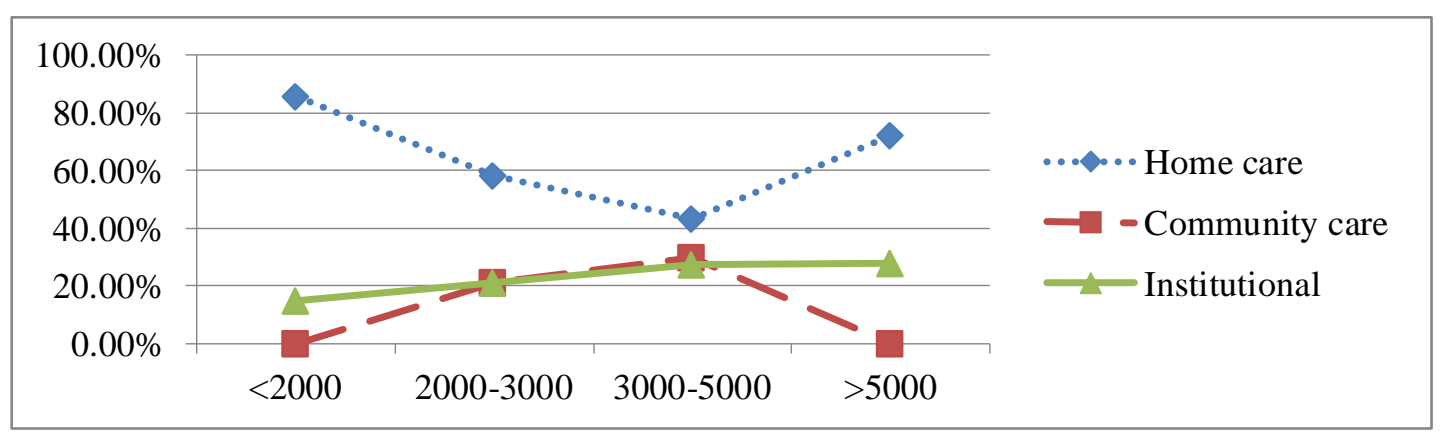

Figure 1 The Choice of Old people's Pension Pattern under Different Income Levels 
Influence on the choice of endowment way through the questionnaire survey in different regions of the elderly living way are shown in Table 5, living in the town of elderly people living alone accounted for $56 \%$, accounted for $44 \%$ of life and children living in rural areas; the elderly living alone accounted for $28 \%$, and children accounted for $72 \%$ of life, the rural life of the elderly and their children life is far more than those who live alone, such a way of living of the rural elderly and children contact more, influenced by the traditional concept of retirement, the elderly and children always think that only children filial or helpless old people to live in a nursing home, so more inclined to choose family pension.

Table 5 The Choice of Pension mode in Different Regions and Different Living Conditions

\begin{tabular}{|c|l|c|c|c|c|c|}
\hline \multirow{2}{*}{ Region } & \multirow{2}{*}{ Living conditions } & \multirow{2}{*}{ Number } & \multirow{2}{*}{ Proportion } & \multicolumn{4}{|c|}{ Pension mode } \\
\cline { 4 - 7 } & & & & Home care & Community care & Institutional \\
\hline \multirow{2}{*}{ Urban } & Live alone & 101 & $56 \%$ & $59(58 \%)$ & $8(8 \%)$ & $34(34 \%)$ \\
\cline { 2 - 7 } & Live with children & 78 & $44 \%$ & $73(94 \%)$ & $5(6 \%)$ & 0 \\
\hline \multirow{2}{*}{ Rural } & Live alone & 21 & $28 \%$ & $7(33 \%)$ & $6(29 \%)$ & $8(38 \%)$ \\
\cline { 2 - 7 } & Living with children & 55 & $72 \%$ & $46(84 \%)$ & $3(5 \%)$ & $6(11 \%)$ \\
\hline
\end{tabular}

Except living styles, family structure will also have an impact on the elderly's willingness in choosing pension models. As shown in Table 6,the number of children and filial piety of children have effects with different extents. In Figure 3, the proportion of family pension choice decreases and the proportion of pension choice increases as the number of children increases, which indicates that the number of children is large, and the phenomenon of shirking the responsibility of supporting the elderly may be avoided, so that the proportion of the choice of pension institutions is significantly improved.

Table 6 The effct of the Number of Children on the Old People's Choice of the Way of Providing for the Aged

\begin{tabular}{|c|c|c|c|c|c|c|}
\hline \multirow{2}{*}{ Region } & \multirow{2}{*}{$\begin{array}{c}\text { Number of } \\
\text { children }\end{array}$} & \multirow{2}{*}{ Number } & \multirow{2}{*}{ Proportion } & \multicolumn{4}{|c|}{ Pension mode } \\
\cline { 3 - 7 } & 1 个 & 55 & $31 \%$ & $40(73 \%)$ & $3(5 \%)$ & $12(22 \%)$ \\
\hline \multirow{3}{*}{ Urban } & 2 个 & 66 & $37 \%$ & $49(74 \%)$ & $5(8 \%)$ & $12(18 \%)$ \\
\cline { 2 - 7 } & 3 个 & 58 & $32 \%$ & $43(74 \%)$ & $5(9 \%)$ & $10(17 \%)$ \\
\hline \multirow{3}{*}{ Rural } & 1 个 & 6 & $8 \%$ & $6(100 \%)$ & 0 & 0 \\
\cline { 2 - 7 } & 2 个 & 36 & $47 \%$ & $27(75 \%)$ & $6(17 \%)$ & $3(8 \%)$ \\
\cline { 2 - 7 } & 3 个 & 34 & $45 \%$ & $20(59 \%)$ & $3(9 \%)$ & $11(32 \%)$ \\
\hline
\end{tabular}

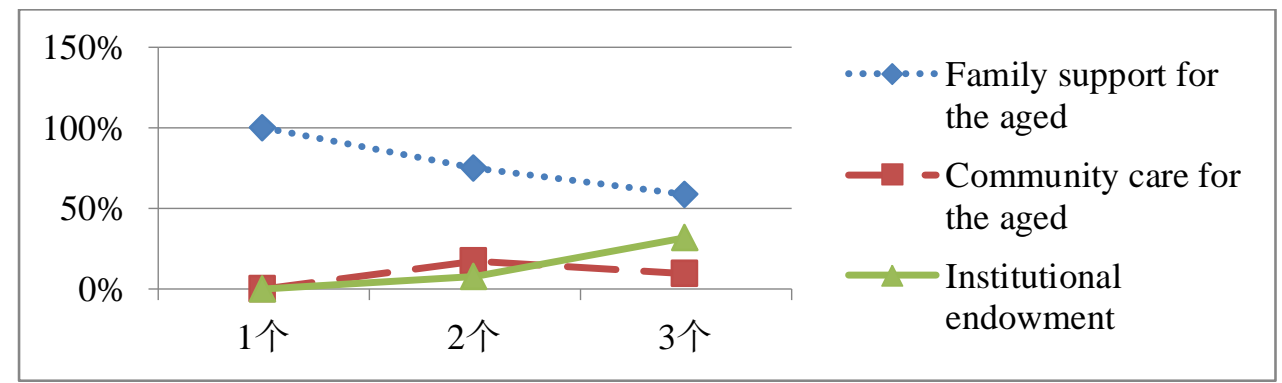

Figure 4 Trend Map of Rural Elderly Choosing Different Ways of Providing for the Aged

Data analysis on the research results of the connotation of pension demand. According to the survey results, according to the age and income of two dimensions for hierarchical, such as table 7 and table 8 , table 7 shows that with the growth of age, the elderly demand for medical conditions and professional care is on the rise. Table 8 shows that the demand for food richness, quiet surroundings, and recreational richness has increased significantly with the increase in income levels. 
Table 7Elderly Needs Statistics of Different Age Groups

\begin{tabular}{|l|l|l|l|l|l|l|l|l|}
\hline \multirow{2}{*}{ Needs of the elderly } & \multicolumn{9}{|c|}{ Age } \\
\cline { 2 - 11 } & $50-55$ & $55-60$ & $60-70$ & \multicolumn{1}{l|}{$>$} \\
\cline { 2 - 10 } & Urban & Rural & Urban & Rural & Urban & Rural & Urban & Rural \\
\hline Perfect medical condition & 48 & 4 & 21 & 10 & 27 & 22 & 40 & 38 \\
\hline Nursing specialty & 18 & 0 & 18 & 0 & 23 & 18 & 6 & 19 \\
\hline Meal cleanliness & 30 & 1 & 12 & 6 & 5 & 5 & 26 & 7 \\
\hline
\end{tabular}

Table 8 RequirementsStatistics for the Elderly under Different Income Levels

\begin{tabular}{|l|l|l|l|l|l|l|l|l|}
\hline Elderly needs & \multicolumn{7}{|c|}{ Income levels } & \multicolumn{7}{|c|}{} & $\begin{array}{l}\text { Proporti } \\
\text { on }\end{array}$ \\
\cline { 2 - 10 } & $<2000$ & Proportion & $\begin{array}{l}2000- \\
3000\end{array}$ & Proportion & $\begin{array}{l}3000- \\
5000\end{array}$ & Proportion & $>5000$ & $33 \%$ \\
\hline $\begin{array}{l}\text { Meal } \\
\text { cleanliness }\end{array}$ & 10 & $7 \%$ & 22 & $51 \%$ & 30 & $68 \%$ & 6 & $7 \%$ \\
\hline Food richness & 20 & $13 \%$ & 3 & $7 \%$ & 3 & $7 \%$ & 5 & $28 \%$ \\
\hline $\begin{array}{l}\text { Quiet } \\
\text { Surrounding } \\
\text { environment }\end{array}$ & 12 & $8 \%$ & 21 & $49 \%$ & 23 & $52 \%$ & 10 & $56 \%$ \\
\hline $\begin{array}{l}\text { Clean living } \\
\text { environment }\end{array}$ & 12 & $8 \%$ & 18 & $42 \%$ & 5 & $11 \%$ & 1 & $5 \%$ \\
\hline $\begin{array}{l}\text { Entertainment } \\
\text { enrichment }\end{array}$ & 15 & $10 \%$ & 18 & $42 \%$ & 25 & $57 \%$ & 10 & $56 \%$ \\
\hline
\end{tabular}

Results Analysis. Through the results of statistics and data of the above analysis, the income level, living status and family structure have different impact on the elderly's choice of pension models. Providing diversified supply system is not only the basis of satisfying the old people's needs for the aged, but also can see the pension mode is single. It can not effectively release the needs of the elderly, and led to the old people have a cognitive bias against each kind of pension mode. Different age of the elderly and the different income of the elderly caused the elderly to pay attention to the content of the service differently. So the distinction between physical condition and income level can be conducive to provide relatively accurate service.

\section{Conclusion}

Due to various constraints, this research in the area and the number of the choice of coverage has some limitations, but can still see from the survey data analysis showed that elderly people choose the pension model, pension service needs attention connotation trend, offer reference to the connotation construction of these trends can be for the pension services provision and pension services.

\section{Acknowledgements}

This research was financially supported by the Hebei University innovation and entrepreneurship training program (national level 201710075023)

\section{Reference}

[1] W.Li:Urban Problems,Vol.1(2015).No.234,p.67.(In Chinese)

[2] L.Li, Y.J.Chen:Chinese Journal of Gerontology,Vol.37(2017).No.3,p.722.(In Chinese)

[3] Q.Wang:Population Research,Vol.40(2016).No.1,p.98.(In Chinese)

[4] J.H.Huang,F.Li and G.Zhao: China Rural Survey,Vol.4(2014),p.29.(In Chinese)

[5] W.J.Zhang and M.Wei:Population \& Economics, Vol.6(2014).No.207,p.22.(In Chinese)

[6] X.Z.Peng,L.J.Song and J.K.Huang:Population Research,Vol.41(2017).No.4,p.46.

[7] T.J.Chu,M.Wang and S.H.Wang: Population \& Economics, Vol.4(2015).No.211,p.119. 